\title{
Chemical Vapour Deposition for Optical Fibre Technology
}

L. Cognolato

CSELT SpA, Via G. Reiss Romoli 274, 10148 Torino, Italy

\begin{abstract}
At the beginning of the seventies, a break-through took place in the telecommunication research. The introduction of Chemical Vapour Deposition technology in the manufacture of optical fibres allowed both technical quality and economical convenience to realise optical networks, thus beginning the telecommunication revolution.

Since that moment, a great development of the CVD techniques has been performed, introducing several methods to produce fibres with geometry and optical properties optimised for different applications.

An overview of the different methods is given, and the problems which have been to be solved in these years are described.
\end{abstract}

\section{ENTRODUCTION}

The first complete theoretical analysis of electromagnetic propagation in dielectric cylinders was performed in 1910 [1]. However, it was only in the 1950s that optical fibres began to find practical applications, as "fiberscopes", flexible bundles for image transmission. But it was not until 1966 that their use in the field of optical communications was considered feasible. The reason of that was the attenuation exhibited by glass fibres available at that time was in the range of thousands of $\mathrm{dB} / \mathrm{km}$. This allowed transmission only over short distances.

In 1966 it was demonstrated [2] that the attenuation found in glass employed for optical fibres was not a basic property of material but was produced by the presence of impurities, mainly metallic ions and OH groups. The intrinsic material loss is essentially due to Raleigh-type scattering, which decreases as the fourth power of wavelength. Since that loss is very low, reducing the impurity content would make it possible to attain much lower losses than those typically encountered.

At that point, it was recognised that an attenuation of $20 \mathrm{~dB} / \mathrm{km}$ for glass fibres was a limit beyond which practical application to long distance transmission became feasible. In 1970 Corning Glass Work succeeded in fabricating optical fibres hundreds of metres long with loss under $20 \mathrm{~dB} / \mathrm{km}$ [3]. The technique consisted of depositing by chemical synthesis in vapour phase a thin layer of very pure, doped silica material inside a fused silica tube, which formed the basis for the modem low loss fibre production technology. Since the first important result of Corning, a continuous progress in loss decrease was obtained, very close to the theoretical minimum loss of $0.157 \mathrm{~dB} / \mathrm{km}$ [4] at $\lambda=1.55 \mu \mathrm{m}$.

\section{THE FIBRE STRUCTURE AND THE FABRICATION PROCESS}

The fundamental characteristic of an optical fibre is its capacity of light guiding and confinement, which from the structure point of view means that component materials must be very transparent at the transmission wavelength and that the refractive index of the internal glass (cone) is higher than the surrounding one (cladding), as shown in fig. 1. 


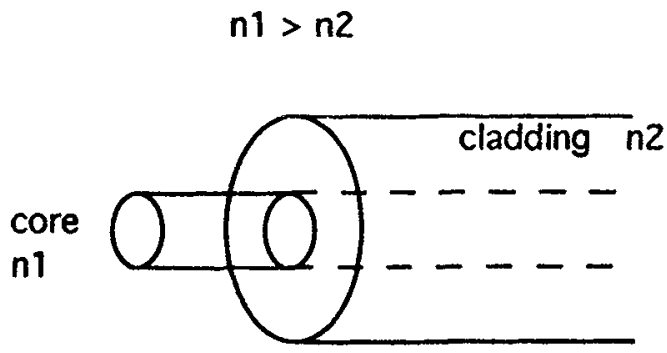

optical fibre

Fig. 1: Structure of an optical fibre

The fabrication process (schematically shown in fig.2) must realise a glass composition obeying to the core-cladding guiding structure, through the manufacture of an intermediate called preform, which has the same structure of the final optical fibre, and which will be drawn into a fibre at the correct diameter $(125 \mu \mathrm{m})$ maintaining the same refractive index profile of the preform [5].

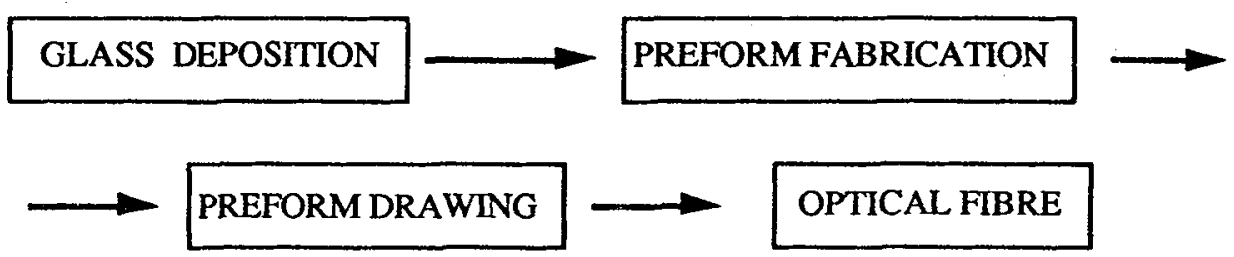

Fig. 2: Scheme of the optical fibre fabrication

Different techniques based on chemical vapour deposition have been employed to manufacture optical fibres: table 1 collects the most used both for research and industrial applications.

TABLE 1. The Vapour Phase Processes

Vapour Phase Processes

Inside Vapour Phase Oxidation (IVPO)

Modified CVD

(MCVD) [9]

(VPP)

$\begin{array}{ll} & \text { PCVD [17] } \\ \text { Plasma CVD } & \text { PECVD [18] } \\ & \text { PICVD [19] } \\ & \text { SPCVD [20] }\end{array}$

Outside Vapour Phase Oxidation

Outside Vapour

(OVPO) Vapour Axial

Deposition (OVD) [21]

Deposition (VAD) [23]

SPCVD [20] 


\section{THE PROCESS CHEMISTRY}

\subsection{The silica glass}

After a first phase in which several kinds of glasses have been experimented, melting the glass just before the drawing process (double crucible method [6]), very low attenuation has been produced by synthesising high silica content glass. The content of silica in the core approximately varies from $85 \%$ in the multimode fibres to $100 \%$ in pure silica core fibres. The other compounds which go to make up the composition are thus used in relatively low percentages and are (not very properly) called dopants.

The structure of silica, both in polymorphic crystalline and vitreous forms, is based on elementary tethraedral cell with Silicon at the centre, surrounded by four Oxygen atoms bridging other Silicon atoms. In vitreous silica, the lack of a systematic arrangement of these elementary cells and a certain degree of distortion in the tethraedrons gives rise to an open structure, with low density (compared to the homologous crystalline one) which explains the high permeability to light gases. The presence of imperfections, like nonbridging oxygen, influences the chemical and physical properties of the glass.

Stability of silica in the range $-50 /+70^{\circ} \mathrm{C}$ (thermal expansion coefficient: $5.5 \cdot 10^{-7} \mathrm{O}^{-1}$ ) makes it ideal for the telecommunication applications, just like its high resistivity $\left(10^{18}\right.$ $\Omega . c m)$ and its fracture strength (70 MPa).

To achieve any guiding structure, it is necessary to produce a refractive index profile, which is accomplished by introducing percentages of compatible dopants in the silica glass networks, in order to modify the refractive index of the core and/or of the cladding.

Fig. 3 shows the effects of some compounds, among them only Fluorine and Boron Oxide reduce the refractive index of silica, and are used in the doping of the cladding. Some of them, i.e. Phosphor Oxide and Boron Oxide, increase the attenuation at the telecommunication wavelength, and are no more used in the long distance fibres.

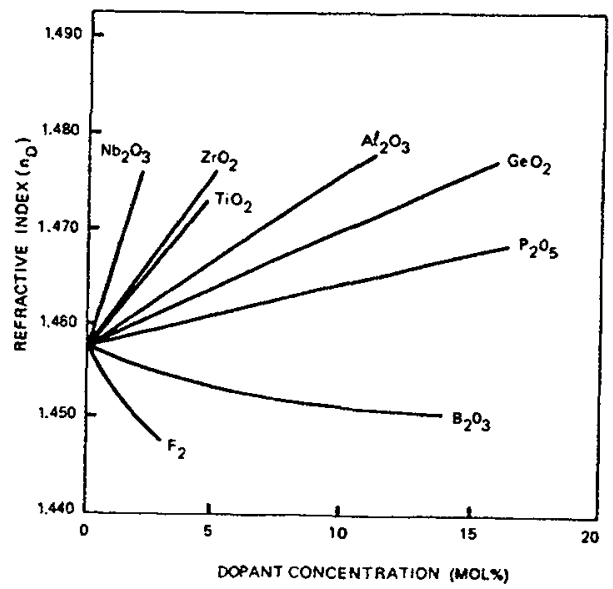

Fig. 3: Silica refractive index vs. dopant concentration (from ref. 5)

\subsection{The deposition mechanism}

The general chemical equation describing the reaction which is involved in the deposition process, in all techniques employed in the optical fibre manufacture is the following oxidation:

$$
\mathrm{MX}_{2 \mathrm{n}}+\mathrm{n} / 2 \mathrm{O}_{2} \Leftrightarrow \mathrm{MO}_{\mathrm{n}}+\mathrm{n} \mathrm{X}_{2}
$$

where $\mathrm{M}=\mathrm{Si}, \mathrm{Ge}, \mathrm{Ti}, \mathrm{P}, \mathrm{B}, \mathrm{Al}$, etc., $2 \mathrm{n}$ is the valence of $\mathrm{M}$, and $\mathrm{X}$ is commonly Chlorine. 
Different methods have been developed to transfer the Halogenated species to the deposition region: usually they are simply evaporated and sublimated. Fig. 4 shows the vapour pressure of some different Chlorides involved in CVD process for optical fibre production.

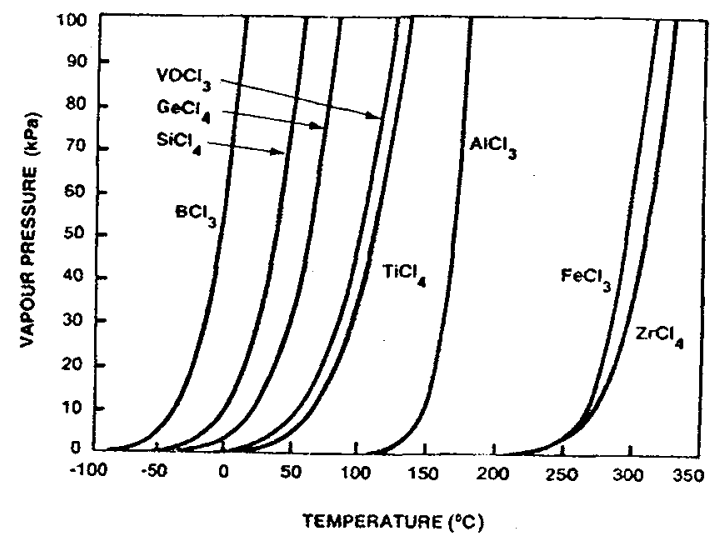

Fig. 4: Vapour pressure vs. temperature of some compounds for fibre optic CVD processes (from ref. 5)

Attention must be provided when the core glass deposition conditions are chosen, because a complex equilibrium system is established, which strongly depends on the equilibria among the several species which are present in the mixture. In particular, the Germanium incorporation depends on temperature, reactant composition, glass flow rates and other process parameters. At low temperature the reactions are controlled by kinetics, but at the higher temperature encountered in the practice the gas concentrations and glass composition are controlled by thermodynamic equilibria.

Fig. 5 [7] shows the effluent composition, determined by infrared spectroscopy, versus the reaction temperature for an $\mathrm{MCVD}$ using $\mathrm{SiCl}_{4}(0.5 \mathrm{~g} / \mathrm{min}), \mathrm{GeCl}_{4}(0.05 \mathrm{~g} / \mathrm{min}), \mathrm{POCl}_{3}$ $(0.016 \mathrm{~g} / \mathrm{min})$ and $\mathrm{O}_{2}(1540 \mathrm{cc} / \mathrm{min})$ : under $1200 \mathrm{oK}$ the effluent concentration are unchanged from the initial values, between 1200 and $1600 \mathrm{OK}$ the reaction of $\mathrm{SiCl}_{4}$ with $\mathrm{O}_{2}$ is indicated by small quantity presence of $\mathrm{SiO}_{2} \mathrm{Cl}_{6}$, while over 1600 \% $\mathrm{K}$ the reaction is complete ( $\mathrm{SiO}_{2}$ does not appear in the plot because it was filtered out to avoid scattering in the optical measurement apparatus). The concentration of $\mathrm{GeCl}_{4}$ in the effluent gases decreases between 1500 and $1700^{\circ} \mathrm{K}$, but above $1700^{\circ} \mathrm{K}$ its concentration remains constant at about $50 \%$ of its initial value. The contemporaneous presence of other dopants (e.g. $\mathrm{POCl}_{3}$ ) in the gaseous mixture influences the $\mathrm{Ge}$ incorporation efficiency as well.

Several profiles can be obtained depositing glasses containing different dopants, which result in optical fibres optimised for various necessities: see fig. 6 . In particular, it can be useful to realise fibres with the cladding refractive index lower than silica; in this case the cladding must be doped with Fluorine (or Boron Oxide, which actually introduces losses) [8]. Freon compounds, $\mathrm{CF}_{4}, \mathrm{SF}_{6}, \mathrm{HF}_{8}$ etc. have been used as Fluorine sources, allowing its incorporation in the glass network, according to the reaction:

$$
\mathrm{F}+-\mathrm{SiO}_{4}-(\mathrm{s}) \Leftrightarrow-\mathrm{SiO}_{3} \mathrm{~F}_{(\mathrm{s})}+1 / 2 \mathrm{O}_{2}
$$

Much attention to the stoichiometric ratio between the reactants must be paid to avoid the etching of silica [9], according to the reaction: 


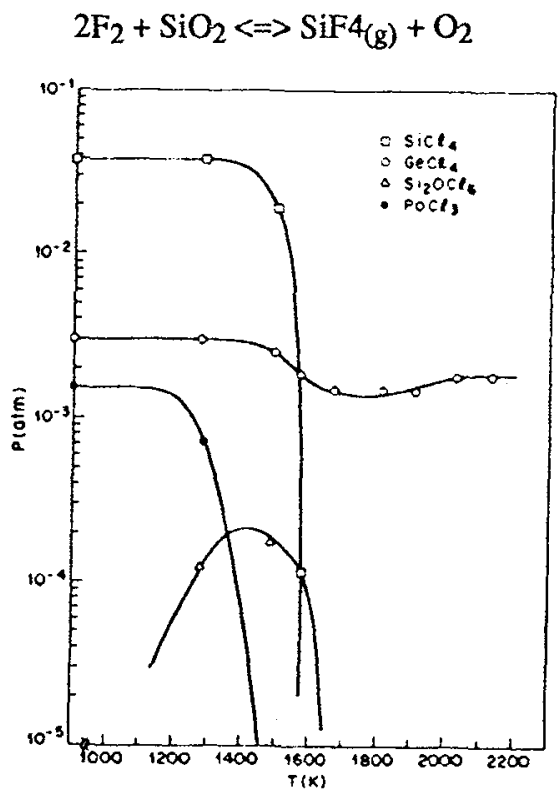

Fig. 5: Effluent gas composition as a function of the deposition temperature (from ref. 7)
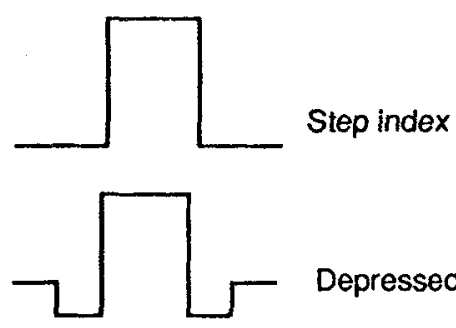

Depressed index

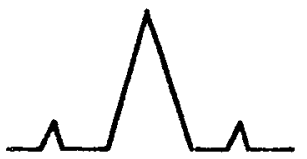

Dispersion shifted
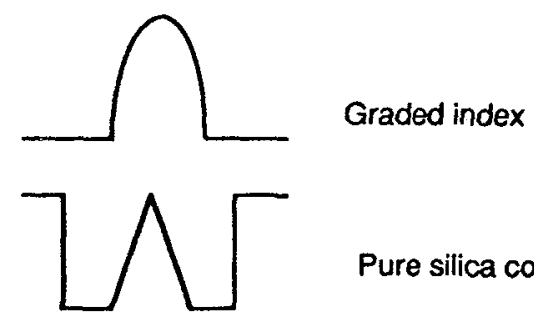

Pure silica core

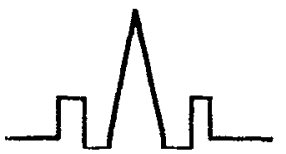

Dispersion flattened

Fig. 6: Different optical fibres refractive index profiles

\section{THE INSIDE VAPOUR PIIASE PROCESSES (IVPO)}

\subsection{Modified Chemical Vapour Deposition (MCVD)}

The MCVD was developed at Bell Labs in 1974 [10], as a development of the deposition method widely used in semiconductor technology. It initially employed Hydride compounds (Silane and Germane), which were successively substituted by Chlorides to avoid $\mathrm{OH}$ formation during the deposition.

The reactants are flown through the reaction tube together with an oxidising-inert mixture of carrying gases $\left(\mathrm{O}_{2}, \mathrm{Ar}, \mathrm{He}\right)$ in controlled quantities by Mass Flow Controllers, and oxidised in proximity of the heated zone (see fig. 7). A short region of the silica tube is 
heated by an external bumer (usually oxy-hydrogen burner) moving in the direction of the reactant flow along the rotating tube, which is mounted on a glass working lathe. The exhaust products ( $\mathrm{Cl}_{2}$ and undeposited silica) are flown outside at the opposite extremity. The reactants, $\mathrm{SiCl}_{4}, \mathrm{O}_{2}$ and various dopants which enter at low temperature, are heated as they approach the hot zone of the traversing torch, with a radial temperature gradient occurring because the gas flowing next to the wall of the containing tube heats up more rapidly and reaches higher temperature than the gas in the centre (see fig. 8). A homogeneous gas phase reaction occurs wherever the gas temperature reaches about 1200 ${ }^{\circ} \mathrm{C}$ and solid particles nucleate from the reaction products. Particle growth occurs as the result of coagulation of colliding particles, as the finely divided solids suspended in the gas pass through the hot zone. Collisions induced by Brownian motion result in aggregates of individual glass particles, which sinter together by viscous flow if the glass is sufficiently fluid [7], up to a diameter of $0.2 \mu \mathrm{m}$.

A soot particle placed in a field with a temperature gradient, tends to move towards the cooled area, as a result of the impact with particles at higher temperature. This phenomenon, called thermophoretic effect, has been demonstrated theoretically and experimentally to govern the deposition on the tube wall downstream the hot reaction zone: the flux of the particles towards the wall is proportional to the temperature gradient and hence the thermophoretic velocity [11].

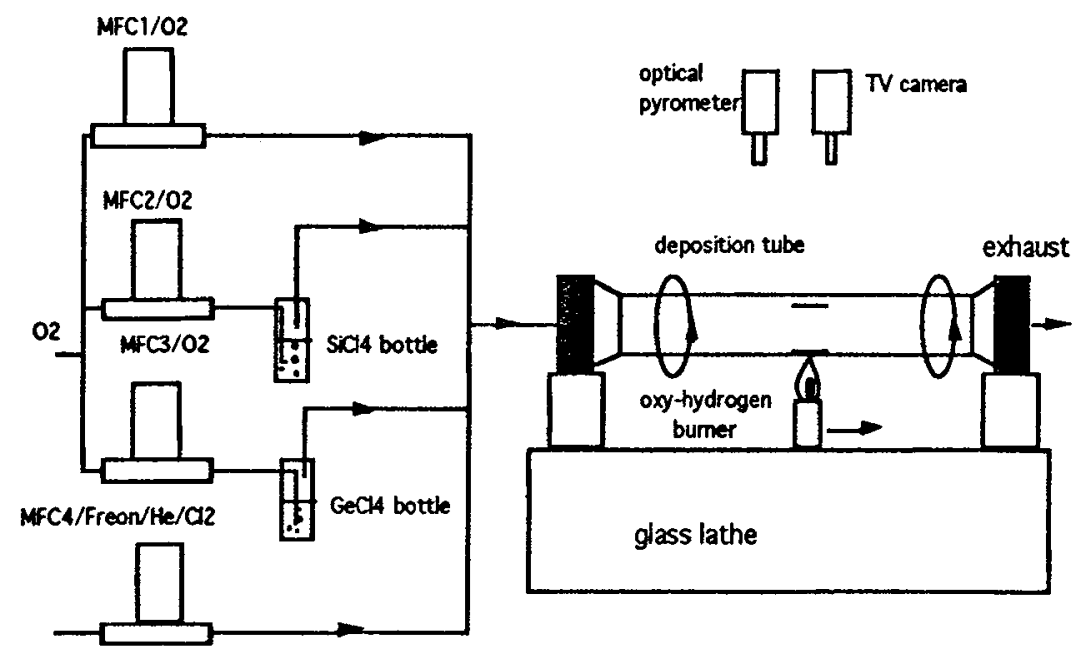

MFC: Mass Flaw Control

Fig. 7: schematic representation of the MCVD plant

Burner movement causes the hot zone to shift onto the zones where silica has been deposited as soot by thermophoresis: it is fused and vitrified by the following cooling. The transparent vitreous layer has generally a thickness varying between 15 and $100 \mu \mathrm{m}$, depending on process flow and temperature.

At the end of the cycle, the burner returns quickly to its initial position and another glass layer deposition can start. Obviously, composition of the gas and process condition can change in order to produce different kind of glass layers, according to the type of fibre to be manufactured. Several cladding layers are deposited, followed by the core layers which are numerous in the case of graded-index multimode fibres, in which reaction gas 
composition are changed at every deposition; in the case of single mode fibres the core is realised in few layers, due to its small final diameter.

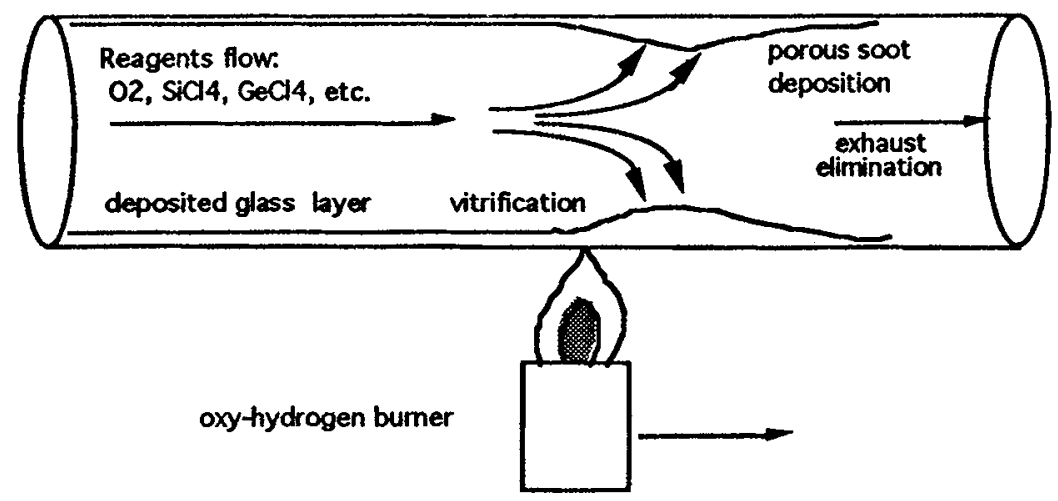

Fig. 8: Deposition process in MCVD technique

At the end of the glass deposition, a collapse phase is started: the tube's internal hole is progressively reduced by successive slower burner passes (typically 5-10) at higher temperature $(1800-2000 \circ \mathrm{C})$, due to the action of surface tension when the high temperature lowers the viscosity of the glass, until a solid cylindrical rod is produced, with a refractive index profile correspondent to the final optical fibre profile.

During this high temperature phase, it can happen that some of the deposited oxides are preferentially evaporated depending on their vapour pressure, causing a dip in the refractive index profile in the centre of the preform. This the typical case of Germanium Oxide which evaporates preferentially from the silica network as $\mathrm{GeO}$, and produces an index dip which can cause some problems in the transmittable bandwidth, though not, usually, to a dramatic extent. It is however possible to compensate for this defect during the process: for instance increasing the Ge content in the collapsing atmosphere during the final phase, or chemically etching the innermost glass layer with fluorinated compounds in the latter collapsing pass to eliminate the dopant depleted glass layers $[9,12]$

The process of deposition is not very efficient ( $50 \%$ for Silica and $10-20 \%$ for Germania), and the deposition rates are very low $(-0.5 \mathrm{~g} / \mathrm{min})$, however the MCVD technique has been largely used by the most of the research laboratories, due to the great versatility of this method, which has received a new impulse in last years due the manufacture of special fibres (e.g. Rare Earth doped fibres) $[13,14]$

\subsection{The plasma processes}

The use of plasma torches in place of flame torches was developed to reduce the $\mathrm{OH}$ introduced in the glass by the flame hydrolysis.

First trials regarded arc torches derived from industrial application (DC plasma torches) used in metallurgy for welding and plasma spraying; however this technique introduces metal contamination due to electrode vaporisation: few $\mathrm{ppm}$ of metals in the glass can increase to a dramatic extent scattering and absorption of the optical fibres.

The method was improved by the introduction of inductive coupled plasma torches [15], in which plasma was generated by induction in a high frequency field (usually $\mathrm{MHz}$ ).

Several plasma techniques have been implemented for IVPO deposition [16]: the first was Plasma CVD, in which a MCVD system is modified in the heating device: the burner is replaced by a microwave cavity resonator supplied by a $2.45 \mathrm{GHz}$ generator. An additional furnace maintains the tube at $1200^{\circ} \mathrm{C}$ (around the glass transition temperature of silica) to reduce stress in the deposited layers and to prevent Chlorine implantation), while a pump usually positioned on the exhaust side maintains the reaction tube at a pressure of 0.1-20 
$\mathrm{kPa}$. The microwave cavity is moved back and forth at the same rate (around $8 \mathrm{~m} / \mathrm{min}$ ) in both directions: an extremely thin layer in comparison with MCVD technique is deposited, but the deposition efficiency is higher $\left(100 \% \mathrm{SiO}_{2}\right.$ and $\left.80-100 \% \mathrm{GeO}_{2}\right)$, due to a different reaction kinetics than an outside thermally activated method. Thus, hundreds of cycles are performed, and less than one $\mu \mathrm{m}$ thick layers are deposited, allowing a very good control of the refractive index profile in the preform [17]. Fig. 9a schematically shows this method.

Plasma Enhanced CVD (PECVD) works at lower frequency (3-5 MHz), and the resonant cavity is replaced by few turns of copper tubing. The reaction tube, where oxidation reaction takes place at atmospheric pressure, is cooled to step up the thermophoretic process and hence efficiency. A soot layer is deposited and subsequently vitrified with an external burner following the inductor: deposition rates up to $7 \mathrm{~g} / \mathrm{min}$ are achieved with good efficiency $\left(90 \% \mathrm{SiO}_{2}\right.$ and $\left.50 \% \mathrm{GeO}_{2}\right)$. This method was introduced as variation of $\mathrm{MCVD}$ in 1980 at Bell Labs [18] and is schematically shown in fig. $9 \mathrm{~b}$.

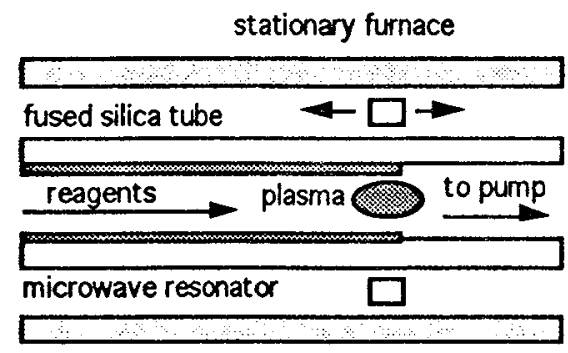

a)

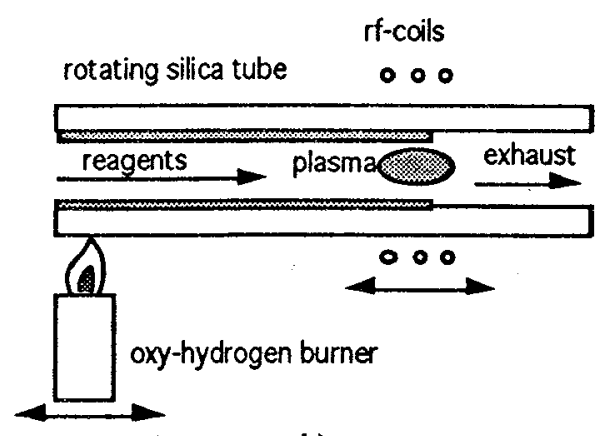

b)

Fig. 9: a) PCVD and b) PECVD methods

Plasma Impulsed CVD (PICVD) is a low pressure method (300 $\mathrm{Pa}$ ) in which the reaction tube, maintained at $1200^{\circ} \mathrm{C}$ and filled with reaction vapours, is contained in a cylindrical waveguide where a pulse generated by a $2.45 \mathrm{GHz}$ magnetron is injected from the exhaust side (fig. 10). The pulse propagates into the guide and ignites the plasma in the vapours, which react and deposit a glass layer in the inner wall of the reaction tube. Upon reaching the opposite side of the waveguide, the pulse is extinguished. Then, a new vapour flow pushes burnt gas towards the exhaust refilling the reaction tube where a new cycle can begin. Pulse frequency $(100 \mathrm{~Hz})$ is the maximum compatible with the rate at which the tube is filled after the previous cycle is extinguished. Deposition rates are low $(0.25$ $\mathrm{g} / \mathrm{min}$ ), but a good efficiency is attained and the great number of layers (100 per sec.) allows a very good index profile definition [19]. More, in this method there are not moving part during the process.

Surface Plasma CVD (SPCVD) was invented in CNET (France), and is a low pressure one $(500 \mathrm{~Pa})$. The reaction tube is maintained at $1200^{\circ} \mathrm{C}$ as in PCVD and PICVD, and a 2.45 $\mathrm{GHz}$ pulse is generated by means of an "illuminator" [20] positioned at the exhaust side, which allows the travelling surface wave is transferred along the tube. The pulse propagates, as in the PICVD, along the tube and a glassy deposit is formed at the inner wall: characteristics similar to PICVD are achieved with this method. 
furnace $(1000 \mathrm{C})$

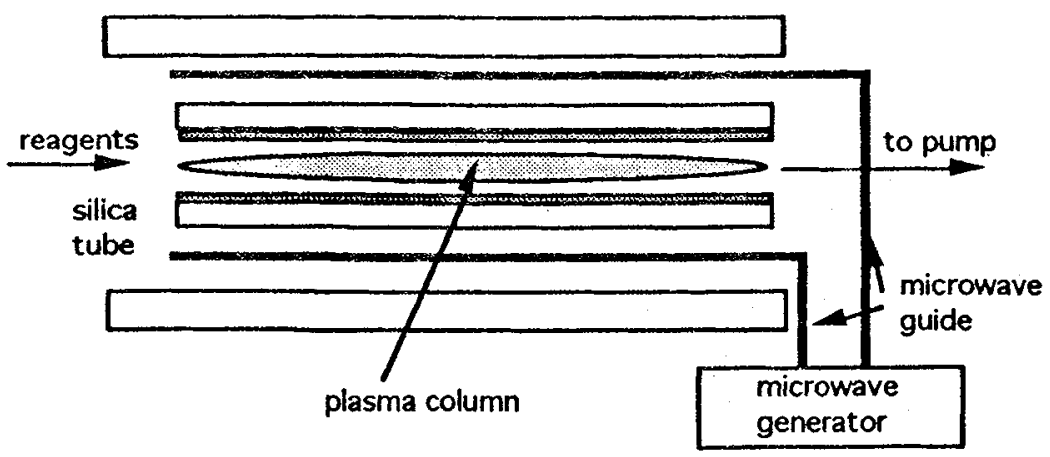

Fig. 10: PICVD method

\section{THE OVPO PROCESSES}

\subsection{Outside Vapour Deposition (OVD)}

OVD has been the first CVD technique to be applied in the optical fibres manufacture, and currently still represents one of the most diffused and important industrial methods. Few marginal modifications have been introduced to the original technique, which was described by J. F. Hyde [21].

The deposition takes place on the surface of a cylindrical rod made of alumina or graphite, which constitutes the support of the preform and is extracted at the end of the deposition process. The rod is rotated and exposed to the flame of a burner, where the reactants are injected together with the fuel gas, Methane or Hydrogen (Fig. 11).

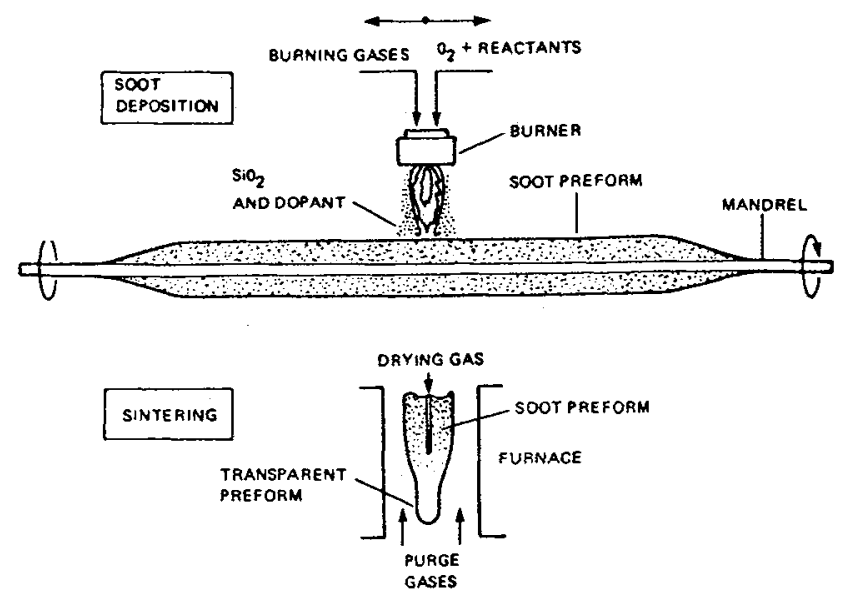

Fig. 11: Schematic representation of the OVD method

The reactants are directed to the burner through vaporising, flow control and mixing systems. They are injected in the flame through the internal orifices, while the combustion gases flow from the external orifices. An intermediate orifice allows an inert gas to guide the reactants towards the hottest zone of the flame, where a flame hydrolysis is carried out, forming a powder of amorphous silica: the particles have diameter around $0.1 \mu \mathrm{m}$. 
The silica particles are deposited on the rotating rod to form a porous cylindrical body phase, the "soot preform", whose density is $15-25 \%$ less than the final preform. Then the support rod is extracted and a consolidation phase (sintering) is performed in a furnace, in order to remove the $\mathrm{OH}$ groups, present in large quantity and to form a compact glass preform.

Actually, this step, carried out in presence of drying gases (like Chlorine) is easier than in other techniques because of the porous state of the "soot preform". Moreover, the deposition phase is performed at a lower temperature, avoiding or greatly reducing the volatilisation of the dopants.

Thousands of layers are deposited, allowing a great accuracy in the construction of the preform's refractive index profile; the efficiency of deposition is increased with the diameter of the cylindrical rod on which deposition takes place: so, while the rates of the core are approximately of $1.8 \mathrm{~g} / \mathrm{min}$, during the cladding deposition the rates rise up to $6 \mathrm{~g} / \mathrm{min}$, producing preforms of $100 \mathrm{~mm}$ in diameter and $800 \mathrm{~mm}$ in length [22].

Increase of productivity is achieved with the stretching method: the preform is drawn in various length which are used as rods of a subsequent deposition process, thus avoiding the extraction of the rod at the end of the deposition.

All the process is carried out in condition of high purity, then the consolidation phase is executed in a furnace with an opportune heating profile, for drying and removing gas bubbles before the consolidation: typical attenuation values are very close to the theoretical value $(-0.20 \mathrm{~dB} / \mathrm{km}$ at $\lambda=1550 \mathrm{~nm})$.

Some disadvantages are due to the large number of steps required to produce a preform, and to the presence of an axial dip formed during the consolidation of the porous tubular preform.

Due to the fact that all the preform glass is synthesised with OVD, unlike IVPO processes where a reaction tube is used, excellent mechanical features are obtained, and complex profiles to produce fibres with special characteristics are easily realised.

Together with the large dimensions of the preform, the good quality of the fibres is the most important reason of the industrial success of the OVD process.

\subsection{Vapour Axial Deposition (VAD)}

The characteristic which distinguishes VAD from other vapour phase deposition processes is the fact that it can be used as a continuous process for production of optical fibre preforms [23].

As for OVD, the VAD process involves several steps: after the "porous preform" fabrication, a dehydration and a consolidation phase follow; but the growing process proceeds axially and the porous preform is gradually grown and extracted from the deposition chamber (see fig. 12), entering in a second chamber where drying gases $\left(\mathrm{He}-\mathrm{Cl}_{2}\right.$ or $\mathrm{He}-\mathrm{SOCl}_{2}$ ) are flown before consolidation phase in an electrical furnace is carried out. The final result, in terms of reduction of $\mathrm{OH}$ groups is excellent [24] and comparable to that achieved with the MCVD process $(0.03 \mathrm{ppm})$.

The most critical part of the VAD plant is the deposition chamber, where both core and cladding are simultaneously deposited, and where the position of the deposition burners must be carefully evaluated in order to obtain the designed refractive index profile. The preform is slowly extracted and rotated on its axis while being pulled, to ensure a perfect symmetry of the deposition. A slight fluctuation in preform position can cause a change in diameter and irregularity in the refractive index profile. To prevent this, the growth zone is carefully maintained stationary and continuously monitored by a TV camera.

Another important factor influencing the quality and the reproducibility of the preform and the regularity of the refractive index is burner shape. The burner depositing the cladding is usually positioned perpendicularly to the growing preform, while the refractive index is produced by acting on the spatial distribution of dopants in the flame. Mixtures of starting compounds, with different dopant concentrations are made to flow in different areas of the burner, thus obtaining also complex profiles, such as in "graded index" multimode fibres.

A careful control of the surface temperature in the growing preform is important: $\mathrm{GeO}_{2}$ in particular needs a temperature between 500 and $800^{\circ} \mathrm{C}$, because below $500^{\circ} \mathrm{C}$ there is not 
incorporation in the glass network, but is deposited in crystalline form which can be sublimated during the consolidation, whilst over $800^{\circ} \mathrm{C}$ the $\mathrm{GeO}_{2}$ concentration drops due to the sublimation caused by its high vapour pressure [25].

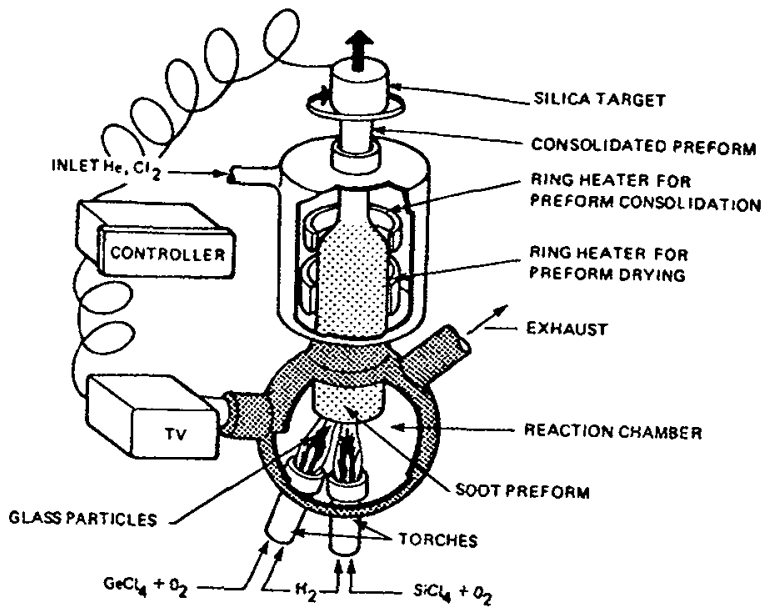

Fig. 12: Schematic representation of the VAD process (from ref. 5)

The major advantages of the VAD processes are the high deposition rate and the ability to produce large preforms: typical deposition rates are around $0.4 \mathrm{~g} / \mathrm{min}$, but methods for increasing this value have been developed, with the addiction of clad deposition burners, or optimising their geometry, e.g. with multi-flame bumers, where a second or third flame are coaxial with the main reagent-rich internal flame. Such a burners' structure allows an increase in the size of solid particles formed [26], permits an increase in flame temperature and an enlargement of the hot zone, with flow conditions remaining equal. In addiction, deposition rates and efficiency have been further optimised by adopting $\mathrm{SiHCl}_{3}$ instead of $\mathrm{SiCl}_{4}$ as the starting reagent, which has made possible to reach total deposition rates of 10 $\mathrm{g} / \mathrm{min}[27]$.

The continuous production of the preform allowed by this process has permitted the fabrication of large size preforms, consisting entirely of synthesised silica (which is believed to improve the mechanical strength of the fibres), from which more than $400 \mathrm{~km}$ of fibres have been produced [28].

One of the major disadvantages of the VAD technology would appear to be complexity of the deposition device, in particular the burner geometry, which must be constructed "ad hoc" for each type of refractive index profile, so causing its limited diffusion in research laboratories, but obtaining a good success in the industry.

The VAD method, patented at the Nippon Telephone and Telegraph Laboratories is currently the most common process in Japan for optical fibres production.

\section{CONCLUSIONS}

Introduction of CVD techniques has allowed the production of low cost, high quality optical fibres for telecommunications. Minimum of attenuation of $0.157 \mathrm{~dB} / \mathrm{km}$ has been reached thanks to the high purity glasses deposited by vapour methods, both by inside than outside techniques, and currently millions of kilometres of CVD fabricated optical fibres have been installed, while the research is continuing to realise special fibres for new photonic applications. 


\section{REFERENCES}

[1] D. Hondros and P. Debye, "Elektromagnetische Wellen an Dielektrischen Drahten", Ann. Physik, Vol. 32 (1910), pp. 465-470

[2] K.C. Kao and G.A. Hockam, "Dielectric fibre surface waveguides for optical frequencies", Proc. IEEE, Vol. 113 (1966), pp. 1151-1158

[3] F. P. Kapron and D. B. Keck, "Radiation losses in glass optical waveguides", Trunk Telecommunications by Guided Waves, London (29 Sept.-2 Oct. 1970)

[4] H. Kanamori et al., "Transmission characteristics and reliability of pure-silica-core single-mode fibres", IEEE Journal of Lightwave Technology, Vol. 4, (1986), p. 1144

[5] Technical Staff of CSELT, Ed. F. Tosco, "Fiber Optic Communication Handbook", Blue Ridge, Pennsylvania, 1990, Chapter 2

[6] H. Lydtin and F. Meyer, "Review of techniques applied in optical fibre fabrication", Acta Electronica, Vol. 22, (1979), pp. 225-235

[7] D. L. Wood et al., "Germanium chenistry in the MCVD process for optical fiber fabrication", Journ. Lightw. Techn., Vol. LT-5, (1987), pp. 277-285

[8] H. Yokota et al., "Ultra low loss pure silica core single mode fibre and transmission experiments", Proc. OFC 1986, Post-deadline paper 3-1, pp. 11-18

[9] L. Cognolato et al., "Fluorine in MCVD optical fibres", Journ. Non-Cryst. Sol., Vol. 93, (1987), pp. 296-302

[10] J. B. MacChesney et al., "Preparation of low loss optical fibres using simultaneous vapour phase deposition and fusion", Proc. 10th Int. Congr. Glass, Columbus, Ohio, (1974), pp. 640-644

[11] P. G. Simpkins, S. Greenberg-Kosinski and J. B. MacChesney, "Thermophoresis: the mass transfer mechanism in modified chemical vapour deposition", J. Appl. Phys. Vol. 50, (1979), pp. 5676-5681

[12] B. J. Ainslie et al.,"Fabrication and evaluation of MCVD singlemode optical fibres with and without central index depression", Electr. Lett., Vol. 18, (1982), pp. 809-811

[13] J. E. Townsend, S. B. Poole, D. N. Payne, "Solution doping technique for fabrication of rare-earth doped optical fibres", El. Lett., Vol. 23, (19870, pp.329-330

[14] L. Cognolato et al., "Fabrication of an active optical fibre by a non-aqueous solution doping method and its characterization", Journ. Mat. Science Lett., Vol. 9, (1990), pp. 1395-1396

[15] K. Nassau and J. W. Shiever, "Plasma torchpreparation of high purity, low OH content fused silica",Ceramic Bulletin, Vol. 54, (1975), pp. 1004-1011

[16] P. Bachmann, "Review of plasma deposition applications: preparation of optical waveguides", Pure and applied Chem., Vol. 57, (1985), pp. 1299-1310

[17] P. Geittner, D. Kuppers and H. Lydtin, "Low loss optical fibres prepared by plasmaactivated chemical vapour deposition (PCVD)", Appl. Phys. Lett., Vol. 28 (1976), p. 645646.

[18] J. W. Fleming, "Progress in plasma preparation of lightguide", Proc. 12th Int. Congr. Glass, (1980), Poster Session

[19] D. Krause, V. Paquet and W. Siefert, "A novel plasma impulse CVD process for the preparation of fiber preforms", Proc. 11 th ECOC/5th IOOC, Venezia, Italy (1985), pp. 7-10

[20] D. Pavy et al., "Fabrication of optical fibres preforms by a new surface-plasma CVD process", Proc. 12th ECOC, (1986), pp. 19-21

[21] J. F. Hyde, "Method of making a transparent article of silica", U.S. patent 2272342 (February 10, 1942), filed August 27, 1934

[22] G. J. Koel, "Technical and economic aspects of the different fabrication processes", Ann. Telecom., Vol. 38, (1983), pp. 36-46

[23] T. Izawa, T. Miyashita and F. Manawa, "Continuous fabrication of hogh silica fibre preform", Proc. 1st IOOC, Tokio, Japan, (1977), p. 375

[24] T. Edahiro et al., "OH ion reduction in VAD optical fibres", Electr. Lett., Vol. 5 , (1979), pp. 482-483

[25] T. Izawa and N. Inegaki, "Materials and processes for fiber preform fabrication vapour axial deposition", Proc. of the IEEE, Vol. 68, (1980), pp. 1184-1187 
[26] H. Murata, "Recent developments in vapour phase axial deposition", Journ. Lightw. Techn., Vol. LT-4, (1986), pp. 1026-1033

[27] H. Suda and M. Horiguchi, "High-rate synthesis mechanisms in the multi-flame VAD method", Proc. 12th ECOC, Barcelona, Spain (1986), pp. 59-62

[28] A. Wada et al., "Fully synthesised single-mode fibre fabrication by two-step VAD process using high rate deposition burners", Proc. 13th ECOC, Brighton, England (1987), pp. 159-162 
